NASA Technical Memorandum 83700

\title{
ICAN: Integrated Composites Analyzer
}

P. L. N. Murthy and C. C. Chamis

Lewis Research Center

Cleveland, Ohio

Prepared for the

Twenty-fifth Structures, Structural Dynamics and Materials Conference cosponsored by the AIAA, ASME, ASCE, and AHS

Palm Springs, California, May 14-16, 1984 


\section{TABLE OF CONTENTS}

SUMMARY .............................. 1

SYMBOLS............................. 1

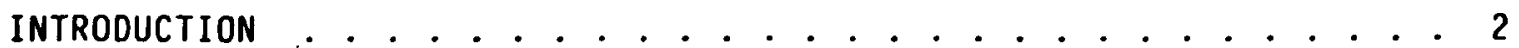

SCOPE AND DEFINITIONS . . . . . . . . . . . . . . . . . . . . . . 3

THEORIES INCLUDED IN ICAN . . . . . . . . . . . . . . . . . . . 4

ICAN COMPUTER PROGRAM STRUCTURE . . . . . . . . . . . . . . . . . 4

ICAN INPUT DATA PREPARATION . . . . . . . . . . . . . . . . . . . 5

ICAN OUTPUT . . . . . . . . . . . . . . . . . . . . . 6

DATA BASE OF CONSTITUENT PROPERTIES (FBMTDATA.BANK) . . . . . . . . . 7

ICAN EXTENSIONS AND COUPLING ...................... . . . 8

CONCLUSIONS . . . . . . . . . . . . . . . . . . . . . 9

APPENDIX A . . . . . . . . . . . . . . . . . . 10

APPENDIX B . . . . . . . . . . . . . . . . . . . 19

REFERENCES ........................... 20

TABLE I. - ICAN: SAMPLE INPUT DATA ................ 21 
P. L. N. Murthy and C. C. Chamis

National Aeronautics and Space Administration

Lewis Research Center

Cleveland, ohio 44135

\section{SUMMARY}

A computer code ICAN (Integrated Composites Analyzer), has been developed to analyze/design fiber composite structures. The program includes composite mechanics theories which resulted from extensive research that has been conducted over the past fifteen years at NASA Lewis Research Center. These theories account for environmental effects and are applicable to intraply hybrid composites, interply hybrid composites and combinations of these, as well as conventional laminate analysis. Key features and capabilities of ICAN are described. A sample input data set and selected output are provided to $11-$ lustrate its generality/versatility and user friendly structure.

SYMBOLS

$C_{f}, C_{m}$

$d_{f}$

$E_{f}, E_{f 11}$,etc.

$E_{m}, E_{m l 1}$, etc.

$G_{f}, G_{f 12}, e t c$.

$G_{m}, G_{m 12}$,etc.

$K_{f 11}, K_{f 22}$

$\mathrm{K}_{\mathrm{m}}$

$K_{V}$

$M_{x}, M_{y}, M_{x y}$

$N_{x}, N_{y}, N_{x y}$

$N_{f}$

$N_{\ell C}$

$\mathrm{N}_{\mathrm{ms}}$

$N_{\ell}$

$\mathrm{S}_{\mathrm{fT}}, \mathrm{S}_{\mathrm{fC}}$

$\mathrm{S}_{\mathrm{mT}}, \mathrm{S}_{\mathrm{mC}}, \mathrm{S}_{\mathrm{mS}}$

$T_{c u}, T_{g d r}, T_{u}$

$\alpha_{f}, \alpha_{f l 1}$, etc.

$\alpha_{m}$ fiber and matrix heat capacities

fllament (fiber) equivalent diameter

elastic constants of fiber

elastic constants of matrix

fiber shear modulus

matrix shear modulus

fiber heat conductivities

matrix heat conductivity

void heat conductivity

applied bending moments

applied membrane forces

number of fibers per end

number of load conditions

number of material systems

number of layers

fiber tensile and compressive strengths

matrix tensile, compressive and shear strengths

cure temperature, dry glass transition temperature and use

temperature

thermal expansion coefficients of fiber

thermal expansion coefficient of matrix 


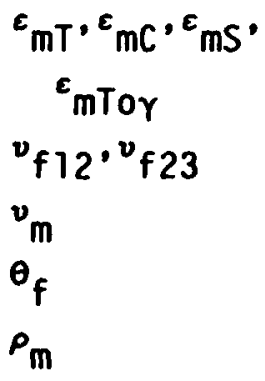

matrix allowable strain limits

fiber Poisson's ratios

matrix Poisson's ratio ply orientation angle

fiber mass density

matrix mass density

\section{INTRODUCTION}

The most cost effective way to analyze/design fiber composite structures is through the use of computer codes. Composite analysis computer codes to date have been based mainly on "classical" laminate theory. Over the past fifteen years, extensive research has been conducted at NASA Lewis Research Center to develop composite mechanics theories and analysis methods from micromechanics to new finite elements. These theories and analys is methods account for environmental effects and are applicable to intraply hybrid composites, interply hybrid composites and combinations thereby. Most of these theories are represented by simplified equations which have been corroborated by experimental results and finite element analysis. The composite mechanics theories with their respective simplified equations constitute a structured theory which is: (1) "upward integrated" from material behavior space to structural analysis; and (2) "top-down traced" from structural response to material behavior space (see fig. 1). This structured theory has been incorporated into a computer code called ICAN (Integrated Composites Analyzer). A brief history of the developments pertaining to composite mechanics and related computer codes which led to the evolution of ICAN is described in the following paragraphs.

The importance of and need for a multilevel analysis in designing structural components with multilayered fiber composites were recognized about 20

years ago (ref. 1). A multilevel analysis computer code (MFCA: Multilayered Fiber Composites Analysis) which was found to be efficient in predicting the structural response of multilayered fiber composites (given the constituent materials properties, the fabrication process, and the composite geometry) is documented in reference 2 .

Intraply hybrid composites are logical sequel to conventional composites and to interply hybrid composites. Recentiy, theoretical and experimental investigations have been conducted on the mechanical behavior of intraply hybrids at Lewis Research Center (refs. 3 to 5). The theoretical methods and equations described in these references together with those for hygrothermal effects (ref. 6) have been integrated into a computer code for predicting hygral, thermal and mechanical properties of, and thereby "designing", intraply hybrid composites. This code is identified as INHYD for INtraply HYbrid Composite Design (ref. 7).

The computer code ICAN, is a synergistic combination of the aforementioned computer programs MFCA and INHYD together with several significant enhancements. It utilizes the micromechanics design of INHYO and the laminate theory of MFCA to build a comprehensive analysis/design capability for structural composites. Additional features unique to ICAN are as follows: 
(1) Ply stress-strain influence coefficients

(2) Microstresses and microstress influence coefficients

(3) Stress concentration factors at a circular hole

(4) Predictions of probable delamination locations around a circular hole

(5) Poisson's ratio mismatch details near a straight free edge

(6) Free edge stresses

(7) Material cards for finite element analysis for NASTRAN (COSMIC, MSC) and MARC

(8) Laminate failure stresses based upon first ply failure and fiber breakage criteria, with and without hygrothermal degradation

(9) Transverse shear stresses and normal stresses

(10) Explicit specification of interply layers

In addition, ICAN has its own data base of material properties for commonly used fibers and matrices. The user needs to specify only the coded names for the constituents. The program searches and selects the appropriate properties from its data base. Furthermore, the input data preparation has been simplified substantially through the introduction of partial free-field format to lessen the burden on the user. The output formats have also been improved significantiy for easier interpretation of the results. All these enhancements make ICAN significantly more inclusive and more user-friendly than its predecessors.

The complete documentation of ICAN with compiled listing, user instructions, programmers manual and sample cases for each option is avallable in reference 8 ). Also, the program will be made avallable through COSMIC -Computer Software Management and Information Center, Suite 112, Barrow Hal1, Athens, Georgia 30602. The objective of this paper is to describe the computer code from the engineer's/analyst's usage viewpoint. Therefore, the description is limited to input-output and application versatility.

\section{SCOPE AND DEFINITIONS}

ICAN is primarlly designed to analyze the hygrothermomechanical response/ properties of ftber reinforced/resin matrix type layered composites, given the local membrane loads and bending moments. Three types of layers are recognized by the program. They are: (1) the standard composite system which consists entirely of a primary composite made of one type of fiber and matrix; (2) the intraply hybrid composite system which consists of a primary composite and a secondary composite arranged in a prescribed manner within a layer (for purposes of identification, the primary composite in the hybrid is the one which constitutes the largest volume ratio); (3) the interply layer which consists of the matrix. Up to ten different material systems and one thousand layers (plies, interplies, combinations) can be handled by ICAN at the present time. The number of different loading conditions (forces or displacements) 
that can be handled in one run is ten; however, the limits can be modified with relative ease. In addition, ICAN recognizes moisture and/or temperature gradients through the thickness.

\section{THEORIES INCLUDED IN ICAN}

The complete detalls of the equations in the code are given in reference 8. Prediction of composite hygrothermomechanical properties is achieved through use of the various micromechanics theories mentioned earlier. Laminate properties are obtained through macromechanics and laminate theory. classical laminate theory is used to predict local stresses and strains. The free edge stress calculations are based upon the approach outlined in reference 9 with enhancements to accommodate interply layer and local characteristics of the adjacent ply. The stress concentration factors around a circular hole are obtained using the equations given in reference 10 . The laminate fallure stress analysis utilizes two criteria: (1) the first ply fallure based upon the maximum strength, and (2) the first ply fallure based upon the fiber breakage. Complete laminate fallure analys is is performed using two different piy combined-stress fallure criteria and one interply delamination criterion for each specified load condition.

\section{ICAN COMPUTER PROGRAM STRUCTURE}

The modular structure of the code is lllustrated in the flow chart in figure 2. The varfous modules of the program in the order in which they are called, the inputs to the subroutines, and the generated output from the modules are identified in a symbolic manner. Each module in turn accesses several common subroutines (a few auxiliary subroutines are not shown). A brief description of the multilevel operations performed by ICAN during a typical run is given below.

The first phase of the run consists of assimilating the input data. The geometry, the number/details of loading conditions, the constituent materials with detalis pertaining to the fiber and matrix volume ratios, the primary and the secondary composite contents, and the temperature gradients and moisture content for each layer are read from the user submitted input data. A summary of the input data is printed out along with the input data echo.

The second phase of the run consists of interpreting the user supplied code words for the constituent materials and retrieving the properties from the resident data base of ICAN. These are then supplied to the modules which perform micromechanics analyses and obtain the lamina properties. The lamina properties are returned to the ICAN main program which is the executive module of the code. The modules involved in this phase are IDGER, BANKRD, INHYB (INHYD MAIN), HTM, COMPP, FIBMT and FLEXX.

The last phase of the run consists of integrating the individual layer properties (using laminate theory) to generate laminate properties, and of performing a complete laminate stress analysis. During this phase, several other operations such as generating a summary of laminate fallure stress analysis, free edge stresses, stress concentration factors around a circular hole, etc., are also performed. The modules and subroutines involved in this phase are FESTRE, EDGSTR, MSCBFL, COMSA, GPCFD2, GACD3, NUDIFS, STRCNF, MCRSTR, MINCOF and FLRLD. 
The detailed descriptions of these various subroutines including the governing equations are given in reference 8 .

\section{ICAN INPUT DATA PREPARATION}

The input data for ICAN is supplied through six different card groups of information. Most of these data cards are identified by a mnemonic to indicate the card group it belongs to in the input data deck. Each physical card is divided into fields of eight columns with one entry per field being allowed. The mnemonic is entered in.format $A B$ and the integers in format 18 . The real numbers may be entered anywhere in the appropriate field. The following is a brief description of each card group.

(1) Title card -- Any title of length up to 80 characters including blanks may be supplied on this card.

(2) Starting data card -- This card has a mnemonic 'STDATA'. It contains the overall laminate and loading details. Included are the number. of plies $N_{l}$, the number of different material systems $N_{m s}$, and the number of loading conditions $\mathrm{N}_{\ell c}$.

(3) Booleans -- A set of Booleans 'COMSAT' 'RINDV', 'BIDE' 'CSANB', and 'NONUDF' are defined through these cards. There are 5 cards -- one per each logical variable. The format is $L 6$. The function of each variable is explained below:

(a) COMSAT -- The letter $T$ on the card will direct the program to perform a complete laminate analysis. A letter $F$ would terminate the program prior to performing the laminate stress analysis.

(b) RINDV - - The letter $T$ is entered on the card if the displacements are inputs; otherwise, the letter $F$ is entered.

(c) BIDE -- The letter $T$ is entered on the card if the interply layer contributions on the composite are desired; otherwise, the letter $f$ is entered.

(d) CSANB -- The letter $T$ is entered in the card if the composite has both membrane and bending symmetry; otherwise, the letter $F$ is entered.

(e) NONUDF -- The letter $T$ is entered if the detalled Poisson's ratio differences chart is to be suppressed; otherwise, the letter $F$ is entered.

(4) Ply Descriptors Card Group -- All the cards in this group have a mnemonic 'PLY'. There are $N_{\ell}$ number of cards (corresponding to $N_{\ell}$ number of plies) with eight entries on each card. The first entry is. 'PLY'. The second and third are identification numbers for the ply and the material system respectively. The fourth and fifth are the use temperature $\left(T_{u}\right)$ and the cure temperature $\left(T_{C u}\right)$. The sixth entry is the amount of motsture weight percentage $(M)$. The seventh and the eighth entries are the orientation angle $\theta$ of the ply and the thickness of the ply respectively. A default value of $0.005 \mathrm{in}$. Is taken for the thickness if this entry is missing. The material system identification number should' be 'different not only for 
different composite systems but aiso whenever the use temperature or moisture content vary from ply to ply.

(5) Constituent Materials Descriptors -- All the cards in this group have mnemonic 'MATCRD'. There are $N_{m s}$ numbers of cards with 10 entries in each card. The first entry is 'MATCRD'. The second and the third are coded words for fiber and matrix material of the primary composite. The code words are entered in $2 A 4$ format. For example, the code for AS type fiber is 'AS--' and epoxy matrix is 'EPOX'. A directory of codes for several fibers and matrices is provided in appendix $B$. The user may choose any combination of fiber and matrix for a composite system or incorporate his own as described in the DATA BASE section. The fourth and the fifth entries pertain to the details of the primary composite system. They are the primary fiber volume ratio and the primary void volume ratio, respectively. The next two entries refer to the secondary composite system which is applicable in the case of an intraply hybrid composite ply. It should be the same as the second and third entries for standard composite systems. The next entry is the secondary composite system volume ratio. The last two entries are the fiber volume ratio and the vold volume ratio for the secondary composite system. These are zero when intraply hybrids are not selected.

(6) Load Cards -- All the cards in this group start with mnemonic 'PLOAD'. There are three cards for each loading condition. Thus, the total number of cards are $3 \mathrm{Ne}_{c}$. The first card under each loading condition contains entries $N_{x}, N_{y}$ and $N_{x y}$, the membrane loads, and $T_{h c s} \theta$ the orientation of the loads with respect to the structural axes. The second card contains the bending resultants $M_{x}, M_{y}$ and $M_{x y}$. The last card contains the transverse shear resultant $D M_{X}$ and. $D M_{y}$ and transverse pressures $P_{U}$ and $P_{\ell}$.

A sample set of input data is illustrated in table I for a four ply symmetric laminate. It has two different material systems. The $0^{\circ}$ plies are of AS graphite fiber/intermediate modulus low strength epoxy matrix composite. The $90^{\circ}$ plies are made of a hybrid composite. The primary composite is S-Glass/high modulus high strength epoxy (SGLA/HMHS). The secondary composite is AS graphite/intermediate modulus high strength epoxy. The use and the cure temperatures are $70^{\circ} \mathrm{F}$. The moisture content is zero.

Input data for additional composite systems may be easily prepared. This is done by selecting a desired fiber and matrix from the avallable materials listed in appendix B (FBMTDATA.BANK), and modifying the appropriate entries in the input data sample fllustration.

\section{ICAN OUTPUT}

The ICAN output succinctly summarizes its features. The following is a list of results that are printed out by the program:
(1) ICAN logo
(2) ICAN coordinate systems
(3) ICAN input data echo 
(4) The input data summary

(5) The fiber and the matrix (constituent materials) properties of primary and secondary composites; the ply level properties

(6) The composite 3-D strain-stress and stress-strain relations about the structural axes; MAT9 card for MSC/NASTRAN solid elements

(7) The composite properties

(8) The composite constitutive equations about the structural axes

(9) The reduced bending and axial stiffnesses

(10) Some useful data for finite element analysis

(11) The displacement-force relations for the current load condition

(12) The ply hygrothermomechanical properties/response

(13) The details of Poisson's ratio mismatch among the plies

(14) Free edge stresses

(15) The microstresses and microstress influence coefficients for each different composite material system

(16) Stress concentration/intensity factors around a circular hole

(17) Locations of probable delamination around circular holes

(18) Ply stress and strain influence coefficients

(19) Laminate failure stresses based on the first ply failure/maximum stress criteria

(20) A summary of the laminate failure stresses based upon two alternatives - the first ply fallure and the fiber breakage.

Selected parts of the ICAN output for the sample input data given in table $I$ is shown in appendix $A$.

\section{DATA BASE OF CONSTITUENT PROPERTIES (FBMTDATA.BANK)}

The constituent properties database is a unique feature of the computer code ICAN. Its primary aim is to reduce the burden on user in preparing properly formatted data for the program. The user only needs to specify the coded names for the fiber and matrix. The format of the data has been structured so as to enable the user to introduce new contents or to modify existing entries as appropriate to his needs. Data for four fibers and three matrices are provided in the present package. A brief description follows.

The fiber properties are arranged in five physical cards of length 80 columns. The first card contains a four character code name of fiber in 
format A4. The second through the fifth cards start with a two letters mnemonic to indicate the type of properties that follow. The format on any of these cards is (A4, 7E10.3) except for the second card. The second card is in format (A3, I6, 7E10.3). The mnemonics FP, FE, FT and FS stand for fiber physical, elastic, thermal and strength related properties. The entries on these cards are explained below:

Card 1: Four character coded name for fiber

Card 2: FP $N_{f}, d_{f}, p_{f}$

Card 3: FE $E_{f 11}, E_{f 22}, v_{f 12}, v_{f 23}, G_{f 12}, G_{f 23}$

Card 4: FT $\alpha_{f 11}, \alpha_{f 22}, K_{f 11}, K_{f 22}, C_{f}$

Card 5: FS $S_{f T}, S_{f C}$

The matrix properties are arranged next after the line "OVER END OF FIBER PROPERTIES". They have essentially the same format as those for fiber property cards. There are, however, six physical cards for each matrix material. The mnemonics used are MP, ME, MT, MS and MV. They stand for matrix physical, elastic, thermal, strength related and miscellaneous properties respectively. The format for the first card is (A4) and for the rest of the cards (A3, 7E10.3). The entries in each card are discussed below:

Card 1: Four character coded name for matrix

Card 2: MP $P_{m}$

Card 3: $M E E_{m}, Y_{m}, \alpha_{m}$

Card 4: MT $\mathrm{K}_{\mathrm{m}}, \mathrm{C}_{\mathrm{m}}$

Card 5: MS $S_{m T}, S_{m C}, S_{m S}, \varepsilon_{m T}, \varepsilon_{m C}, \varepsilon_{m S}, \varepsilon_{m T o r}$

Card 6: $M V K_{V}, T_{g d r}$

The data base presently contains properties for T-300 (T300), AS graphite (AS--), S-Glass (SGLA) and HMS (HMSF) fibers. The avallable matrix materials are - high modulus high strength (HMHS), intermediate modulus high strength (IMHS) and intermediate modulus low strength (IMLS) -- which are epoxy type resins. The complete list of properties is shown in appendix $B$.

\section{ICAN EXTENSIONS AND COUPLING}

The program can be extended to predict wave propagation parameters like the bulk and shear wave velocities, properties such as impact resistance and fatigue. The program can be coupled with complex structural analyses codes where it can serve as a preprocessor and a postprocessor. It is planned to couple ICAN with three integrated computer programs under. in-house development: CODSTRAN - Composite Durability Structural Analysis (ref. 11); COBSTRAN - Composite Blade Structural Analysis (ref. 12); and CISTRAN - Composite Impact Structural Analysis (ref. 13). 
A computer program ICAN (Integrated Composites Analyzer) has been developed to perform all the essential aspects of mechanics/analysis/design of multilayered fiber composites. : The program is modular, open-ended and user friendly. It can handle a variety of composite systems having one type of fiber and one matrix as constituents as well as intraply and interply hybrid composite systems. It can also simulate isotropic layers by considering a primary composite system with negligible fiber volume content. This feature is specificaliy useful in modeling thin interply matrix layers. The program can account for hygrothermal conditions and various combinations of in-plane and bending loads. Usage of this code is lllustrated with a sample input and the generated output. Some of the key features of output are stress concentration factors around a circular hole, locations of probable delamination, a summary of the laminate fallure stress analysis, free edge stresses, microstresses and ply stress/strain influence coefficients. These features make ICAN a powerful, cost-effective tool to analyze/design fiber composite structures and components. 
SUMMARY OF IN P U T DATA

FOUR PLY SYMMETRIC LAMINATE. ICAN SAMPLE INPUT DATA.

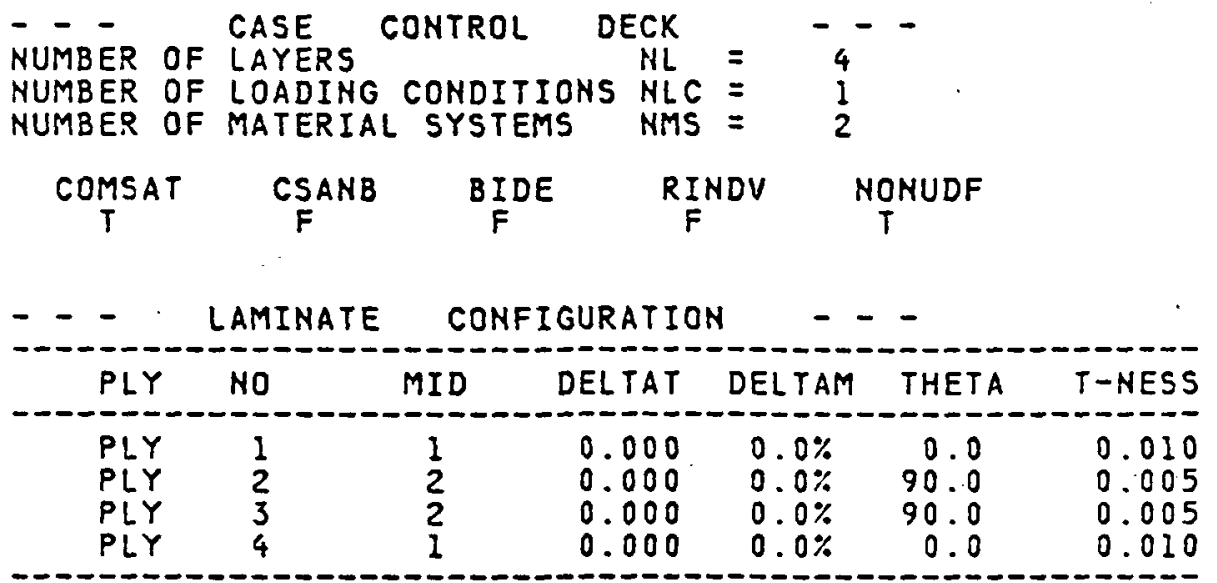

\begin{tabular}{|c|c|c|c|c|c|c|c|c|}
\hline MATCRD & MID & PRIMARY & $\forall F P$ & VVP & SECONDARY & VSC & VFS & VVS \\
\hline $\begin{array}{l}\text { MATCRD } \\
\text { MATCRD }\end{array}$ & $\begin{array}{l}1 \\
2\end{array}$ & $\begin{array}{l}\text { AS--IMLS } \\
\text { SGLAHMHS }\end{array}$ & $\begin{array}{l}0.55 \\
0.55\end{array}$ & $\begin{array}{l}0.02 \\
0.01\end{array}$ & $\begin{array}{l}\text { AS--IMLS } \\
\text { AS--IMHS }\end{array}$ & $\begin{array}{l}0.00 \\
0.40\end{array}$ & $\begin{array}{l}0.57 \\
0.57\end{array}$ & $\begin{array}{l}0.03 \\
0.01\end{array}$ \\
\hline
\end{tabular}

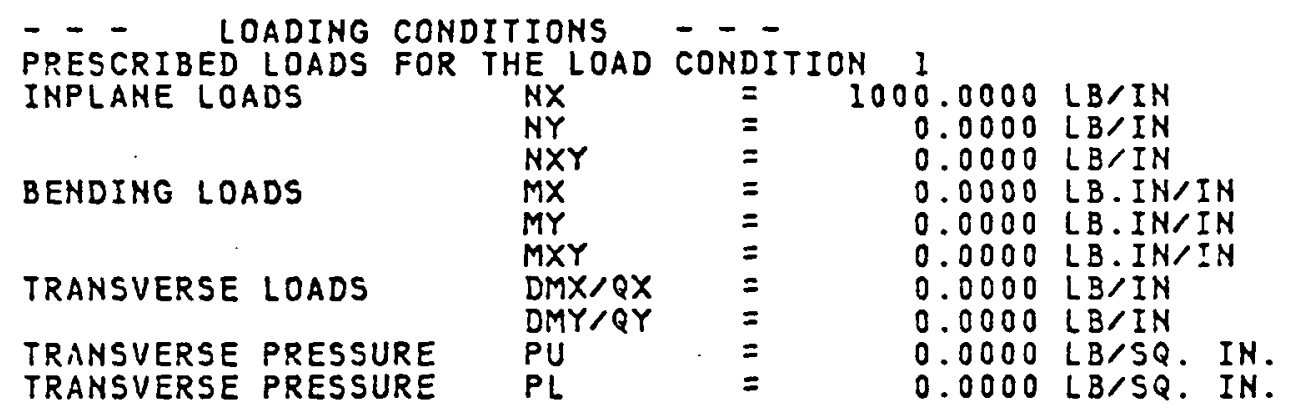




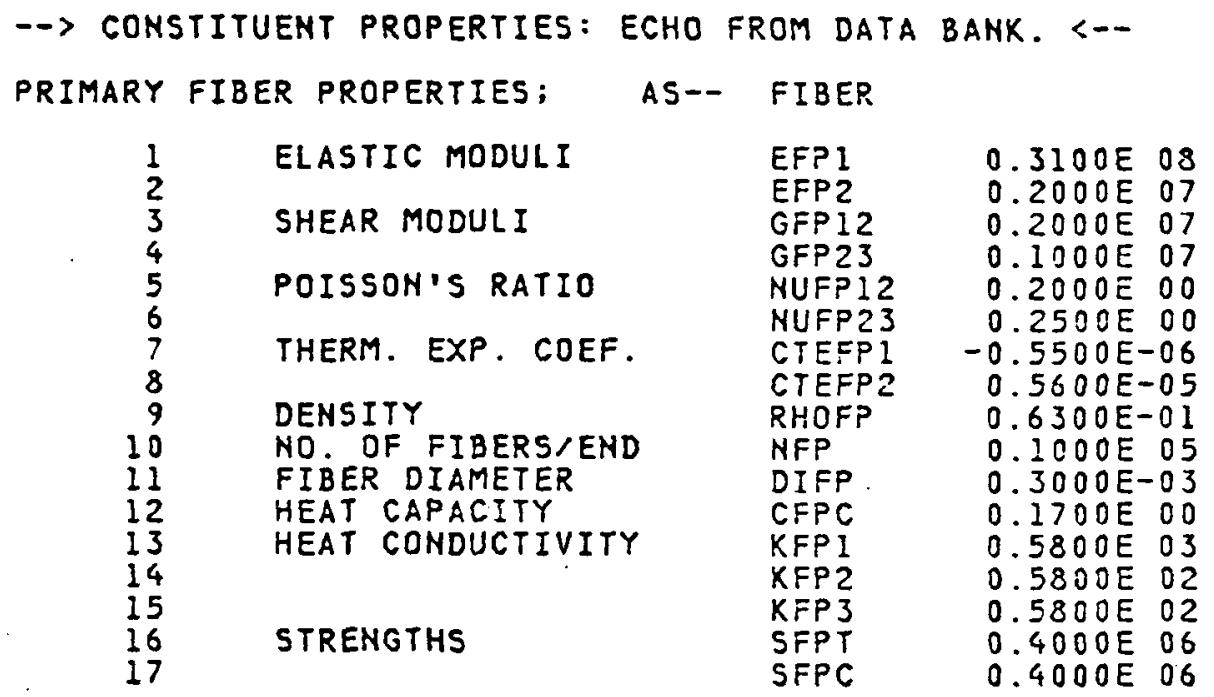

PRIMARY MATRIX PROPERTIES; -

$\begin{array}{ll}1 & \text { ELASTIC MODULUS } \\ 2 & \text { SHEAR MODULUS } \\ 3 & \text { POISSON S RATIO } \\ 4 & \text { THERM. EXP. COEF } \\ 5 & \text { DENSITY } \\ 6 & \text { HEAT CAPACITY } \\ 7 & \text { HEAT CONDUCTIVITY } \\ 8 & \text { STRENGTHS } \\ 9 & \\ 10 & \\ 11 & \text { MOISTURE COEF } \\ 12 & \text { DIFFUSIVITY }\end{array}$

IMLS MATRIX. DRY RT. PROPERTIES.

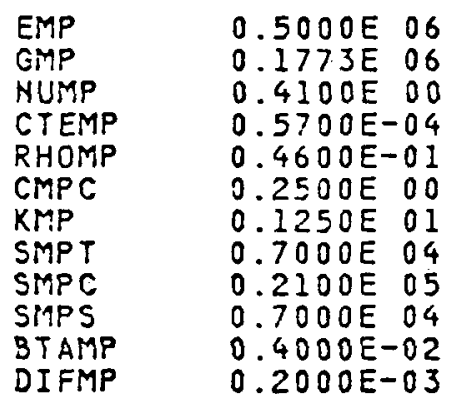


PRIMARY COMPOSITE PROPERTIES; 55/ 43 AS--/IMLS

BASED ON MICROMECHANICS OF INTRAPLY HYBRID COMPOSITES: ELASTIC AND THEPMAL PROPERTIES.

FIBER VOLUME RATIO - 0.550 MATRIX VOLUME RATIO - 0.430 VOID VOLUME RATIO - 0.020
VOID CONDUCTIVITY - $0.22499990 E$ OO

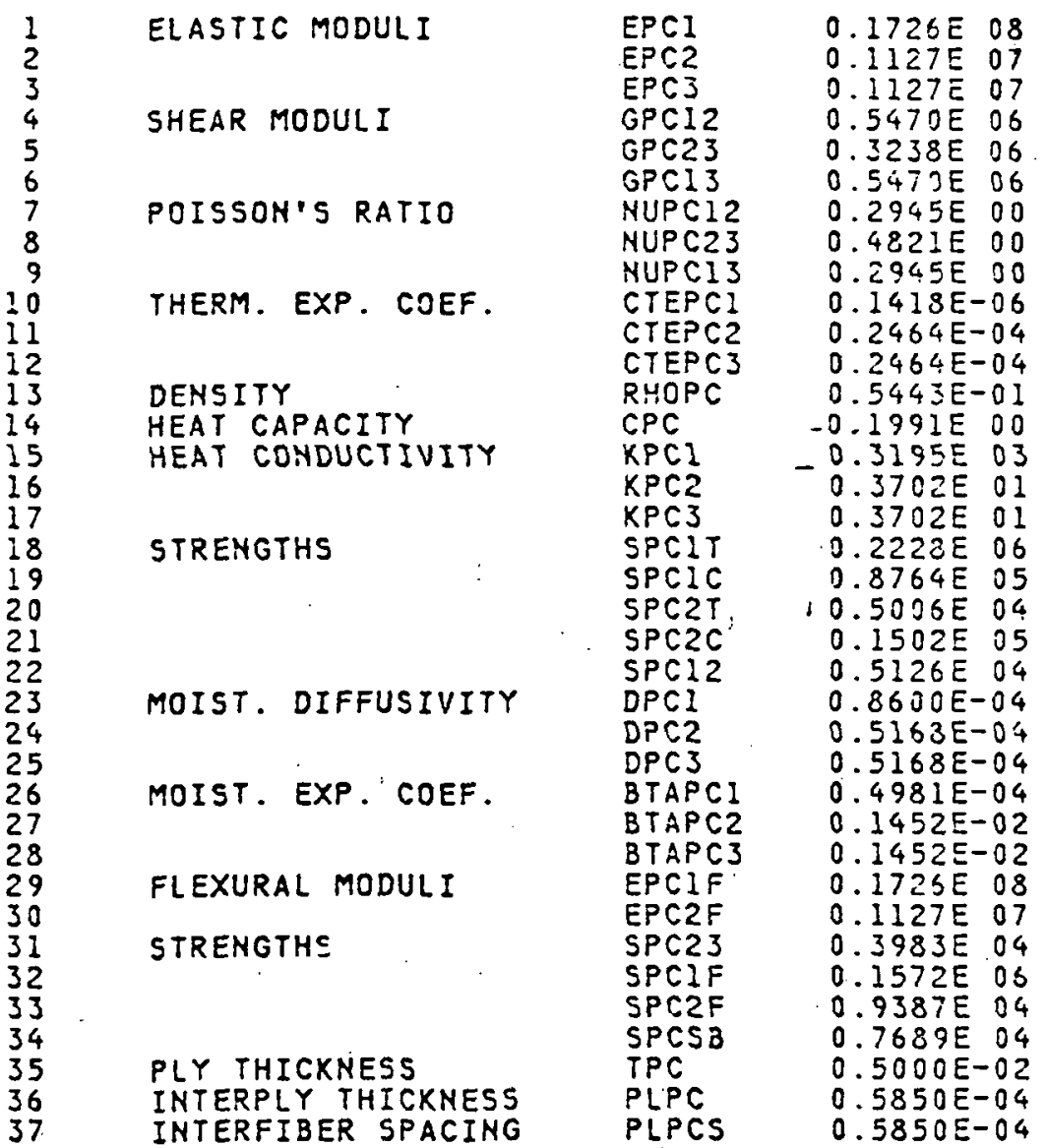


HYBRID COMPOSITE PROPERTIES; $60 / 40$ SGLA/HMHS/AS- /IMHS

BASED ON MICROMECHANICS OF INTRAPLY HYBRID COIIPOSITES: ELASTIC AND THERMAL PROPERTIES.

PRIMARY COMPOSITE VOLUME RATIO - 0.600. SECONDARY COMPOSITE VOLUME RATIO - O. 400

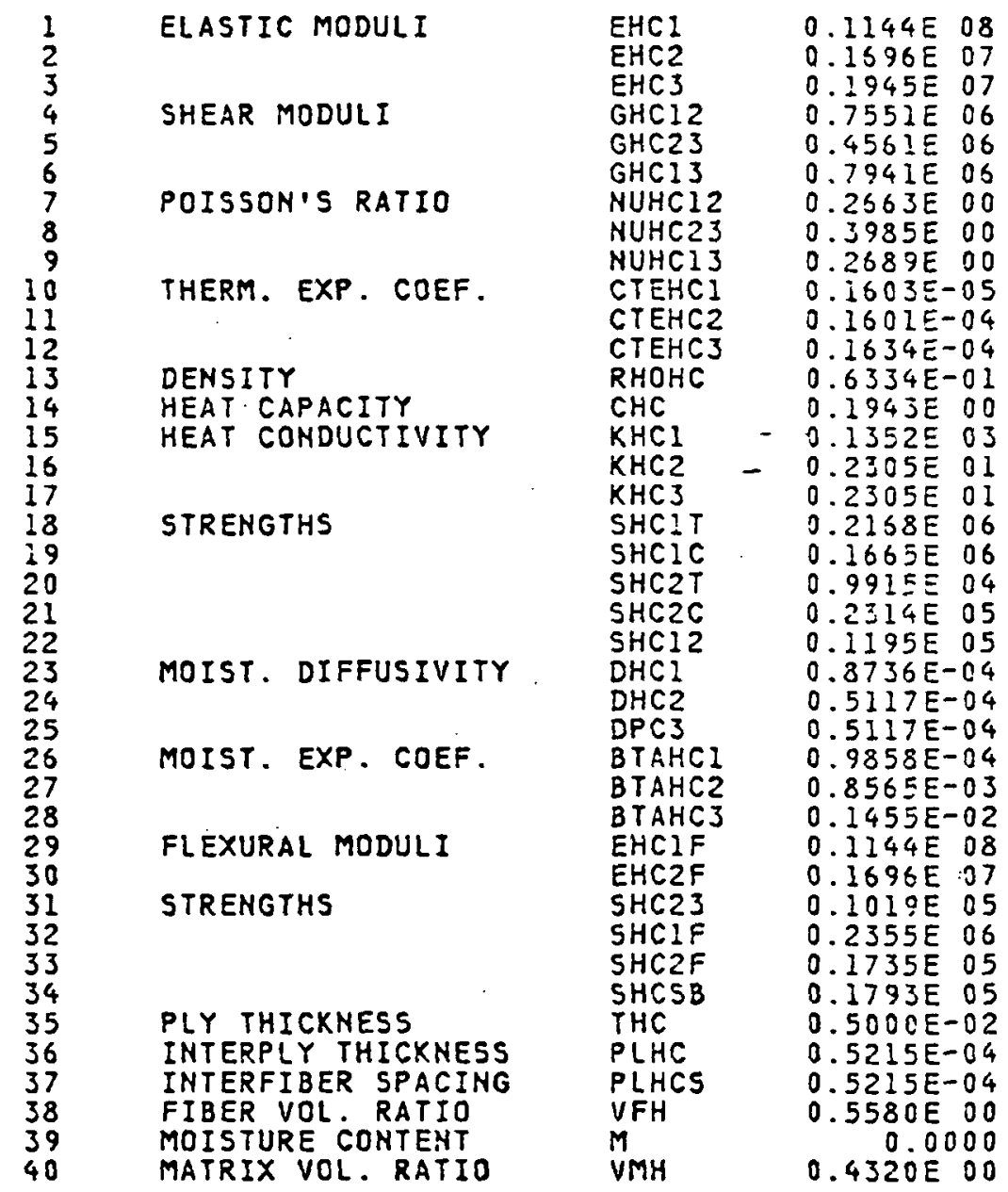




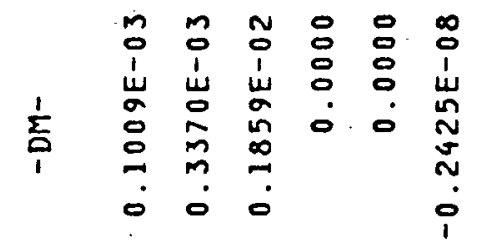

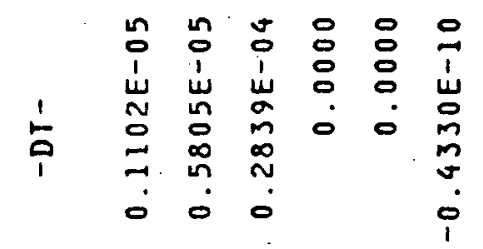

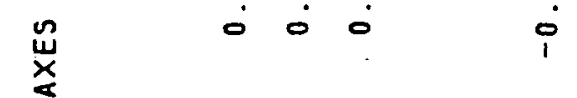

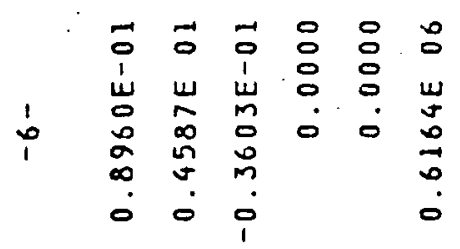

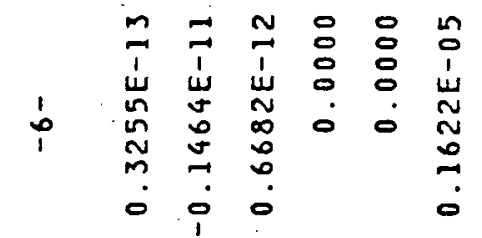

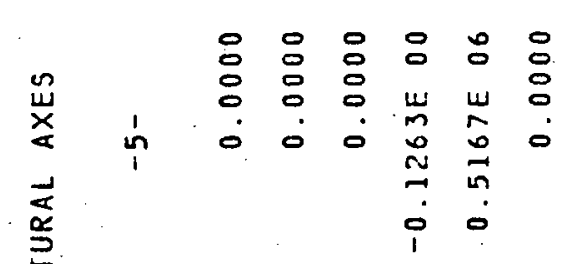

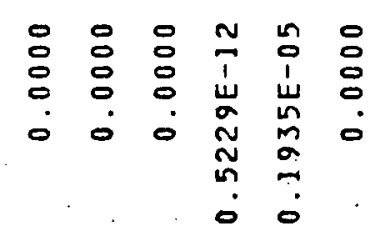

$$
\begin{aligned}
& \begin{array}{llllll}
0 & 0 & 0 & n & N & 0 \\
0 & 0 & 0 & 1 & 1 & 0 \\
0 & 0 & 0 & w & w & 0 \\
0 & 0 & 0 & 0 & N & 0 \\
& 0 & N & 0 \\
& 0 & n & 0 \\
0 & 0 & 0
\end{array}
\end{aligned}
$$

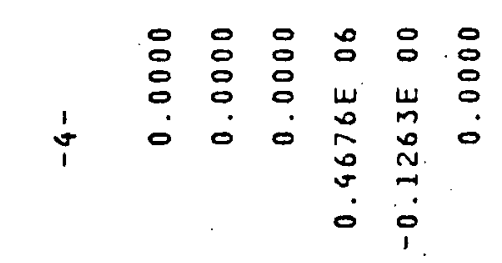

$$
\begin{aligned}
& \begin{array}{llllll}
0 & 0 & 0 & 0 & 0 & 0 \\
w & u & w & 0 & 0 & 1 \\
m & 0 & 0 \\
0 & 0 & 0 & 0 & 0 & 0 \\
0 & 0 & 0 & & 0 \\
0 & 0 & 0 & & 0 \\
0 & 0 & 0 & & 0
\end{array}
\end{aligned}
$$

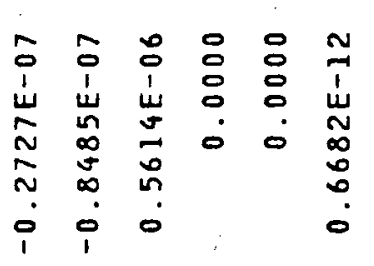

$$
\begin{aligned}
& \text { 告 } 1100
\end{aligned}
$$

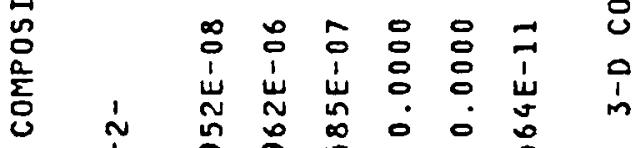

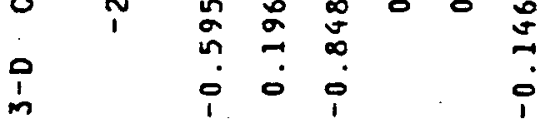

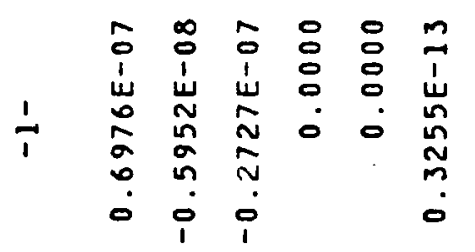

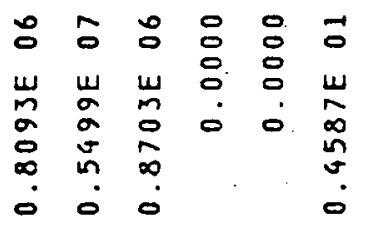

$$
\begin{aligned}
& \text { 웅 } \\
& \text { 山س } \\
& \text { 뭉 } \\
& \text { 品 } \\
& \text { min }
\end{aligned}
$$

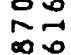

$$
\begin{aligned}
& 00 \\
& \text { 승응 } \\
& \text { w음 } \\
& \text { 응응 } \\
& \text { 응 } \\
& \text { - } 0 . \\
& \text { in. } \\
& \text { 옹응 } \\
& \text { 웅 } \\
& \text { 웅 } \\
& \text { So. } \\
& \text { 茖 }
\end{aligned}
$$

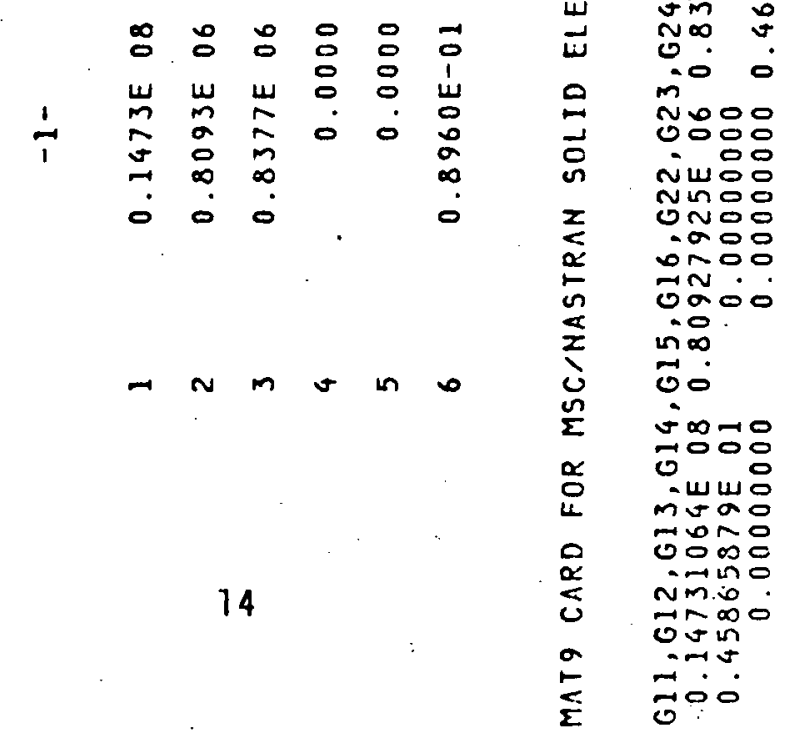


PEDLCED STIFFNESS TATRIX

$3.56 \angle 4 \equiv 36 \quad 3.11233 E=5 \quad 0.52005 E-22$

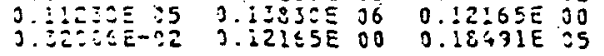

₹EZUCEO ZENOIHG PESIZITIES

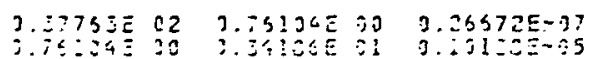

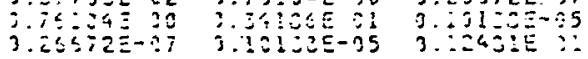

S $0 \therefore E$ USEFUL DATA FOR F.E.A IALYSIS

OSMOOSITE THICYMESS FOR F.E. ALALYSIS $=0.30000 E-01$

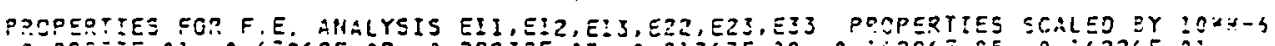

J.

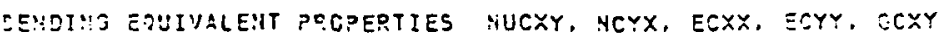

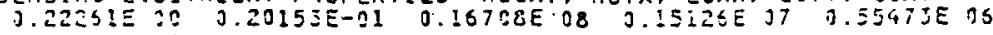

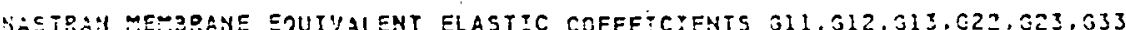

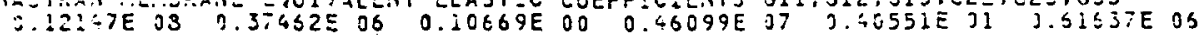

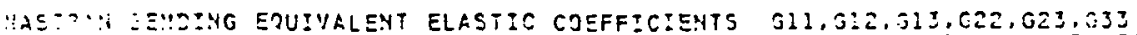

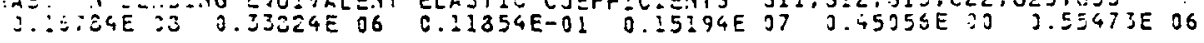

DISP.

DISPLACENENT FORCE RELATIOUS

CO:4BINED FORCES

1

$0.2751 E-02 \quad 0.2751 E-05 \quad-0.2256 E-06 \quad 0.9945 E-12$

3. $13 \times 38-1$

$-\frac{5-}{2}$

$1 E-11-0.2356 E-15$

$0.1000 E \quad 04$

2

$-0.2236 E-93$

$-0.2236 E-06$

$0.7249 E-95 \quad-9.4755 E-10$

$-0.5395 E-11$

3. $29255-19$

$0.1283 E-14$

0.0000

3

$3.9946 E-93$

$0.9946 E-12 \quad-0.4765 E-10 \quad 0.54055-04$

$-0.3466 E-? 6$

$3.2237 E-14 \quad-0.11815-18$

0.2000

4

$0.1813 E-09$

$0.1818 E-12 \quad-0.5895 E-11-0.3466 E-16$

$0.2660 E-0$

$-0.5922 E-0$

$0.4241 E-08$

0.0000

5

$-0.9021 E-08$

$-0.9021 E-11$

$0.2925 E-09 \quad 0.2237 E-14$

$-0.5922 E-0=$

$0.2938 E 00 \quad-0.2385 E-08$

0.0000

$-0.2356 E-1$

$-0.2356 \varepsilon-16$

$0.1283 E-14 \quad-0.1181 E-19$

$0.4241 E-08 \quad-0.2385 E-06 \quad 0.8022 E \quad 00$

0.0000

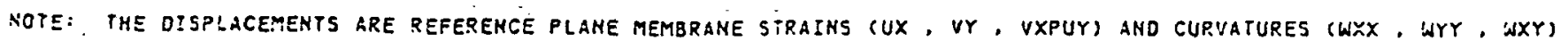




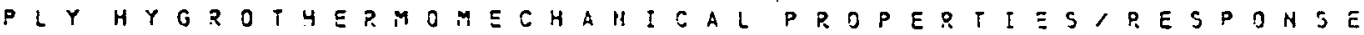

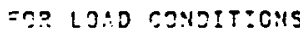

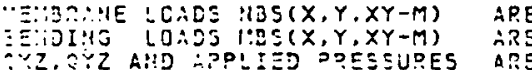

1000

$\begin{array}{lll}00 . & 3 . & 0 . \\ 3 . & 0 . & 0 . \\ 0 . & 0 . & 0 .\end{array}$

$\therefore$ :

LAYEP PPOPERTIES, RO:!S-PROPEPTY, COLUMHS-LAYER.

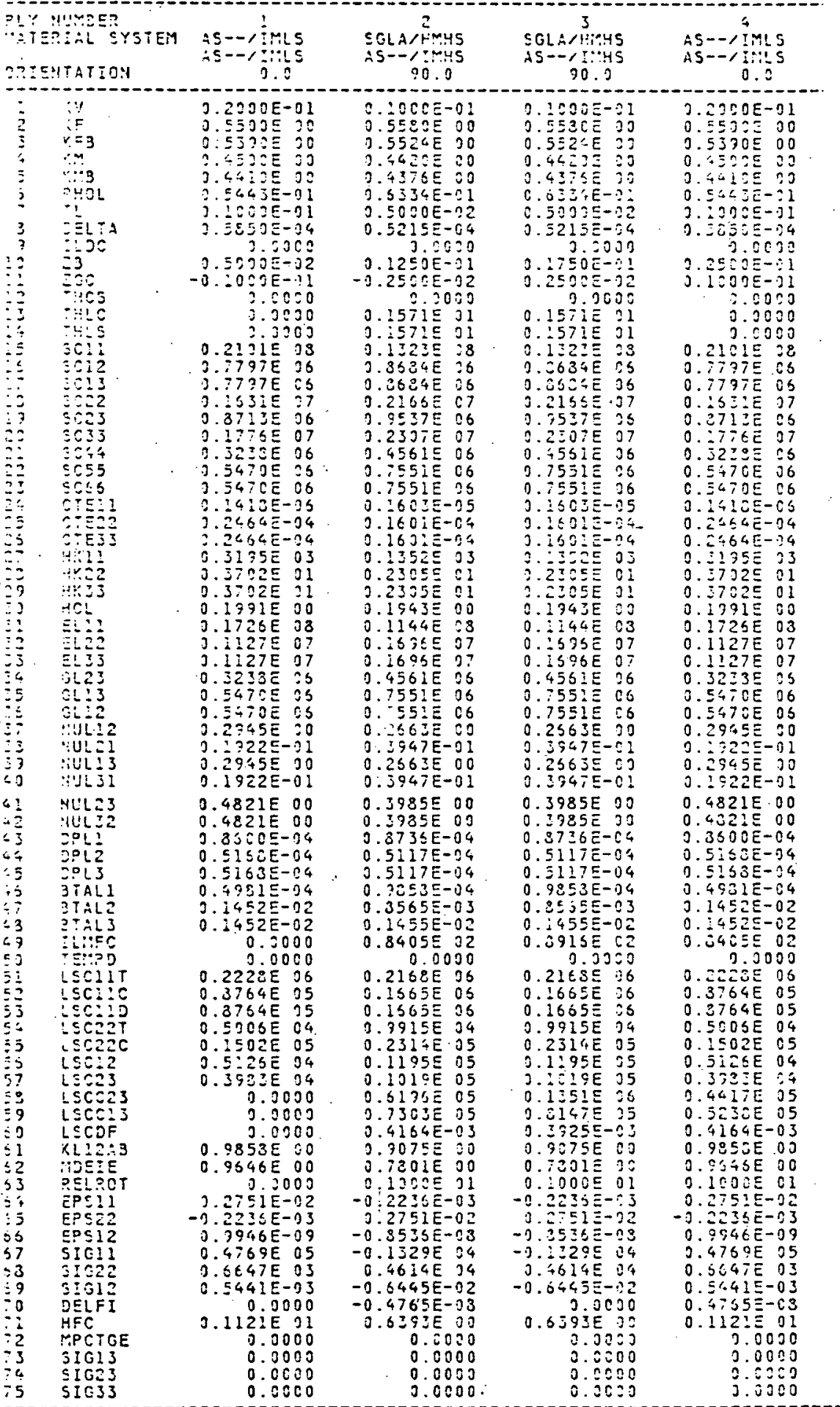


STRESS C O HCE ENTRA T I ON FACTTOR S (AROUMD A CIRCULAR HOLE)

NOTE: KIXX $\rightarrow$ STRESS COHCEIITRATIOH FAOTOR. DUE TO SIGISA XX

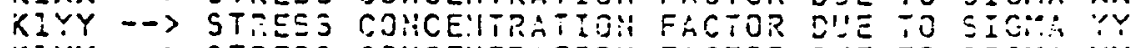

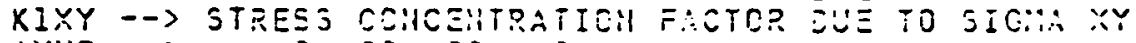
LAYUP $-\rightarrow$ O 90 30 0

\begin{tabular}{|c|c|c|c|c|c|c|c|}
\hline THETA & $K 1 X X$ & $K: Y Y$ & KIXY & THETA & איאוא & :IYYY & K1XY \\
\hline $\begin{array}{l}0.0 \\
5.0 \\
13.0 \\
15.0 \\
20.0 \\
25.0 \\
30.0 \\
55.0 \\
40.0 \\
45.0 \\
50.0 \\
55.0 \\
50.0 \\
65.0 \\
70.0 \\
75.0 \\
80.0 \\
35.0 \\
90.0 \\
95.0 \\
100.0 \\
105.0 \\
110.0 \\
115.0 \\
120.0 \\
125.0 \\
130.0 \\
135.0 \\
140.0 \\
145.0 \\
150.0 \\
155.0 \\
160.0 \\
155.0 \\
170.0 \\
175.0\end{array}$ & $\begin{array}{r}-0.6160 \\
-1.5709 \\
-0.4572 \\
-0.3138 \\
-0.1799 \\
-0.0569 \\
0.0532 \\
0.1556 \\
0.2513 \\
0.3734 \\
0.5138 \\
0.3393 \\
0.9302 \\
1.2764 \\
1.7930 \\
2.6025 \\
3.7933 \\
5.2236 \\
5.9765 \\
5.2257 \\
3.7934 \\
2.6025 \\
1.7980 \\
1.2764 \\
0.9302 \\
0.6099 \\
0.5138 \\
0.3764 \\
0.2613 \\
0.1567 \\
0.05332 \\
-0.0569 \\
-0.1799 \\
-0.3163 \\
-0.4571 \\
-0.5709\end{array}$ & 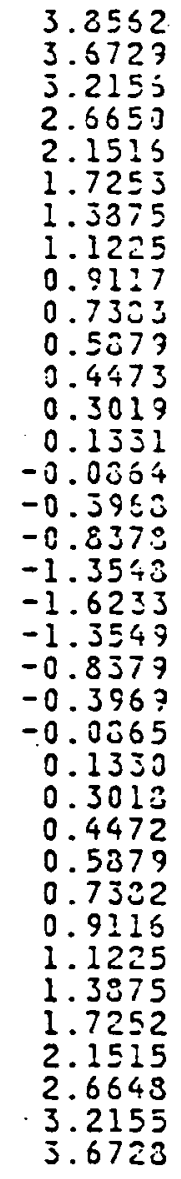 & 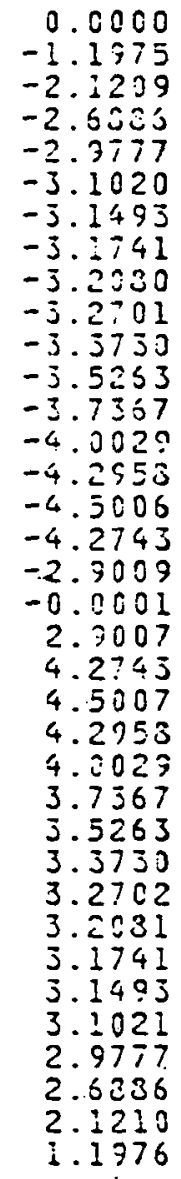 & $\begin{array}{l}130.0 \\
235.0 \\
130.0 \\
335.0 \\
203.0 \\
205.0 \\
210.0 \\
215.0 \\
220.0 \\
225.0 \\
230.0 \\
235.0 \\
240.0 \\
245.0 \\
230.0 \\
235.0 \\
250.0 \\
255.0 \\
270.0 \\
275.0 \\
230.0 \\
235.0 \\
230.0 \\
205.0 \\
300.0 \\
305.0 \\
310.0 \\
315.0 \\
320.0 \\
325.0 \\
330.0 \\
335.0 \\
340.0 \\
345.0 \\
350.0 \\
355.0\end{array}$ & 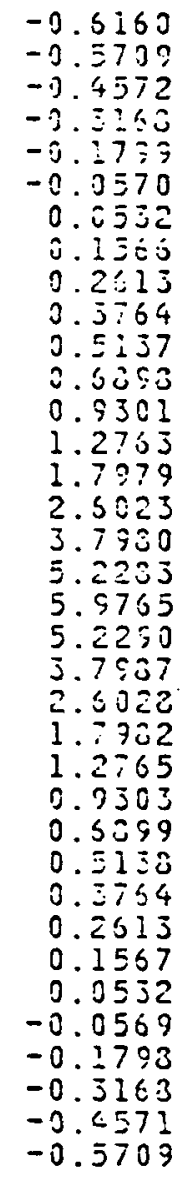 & 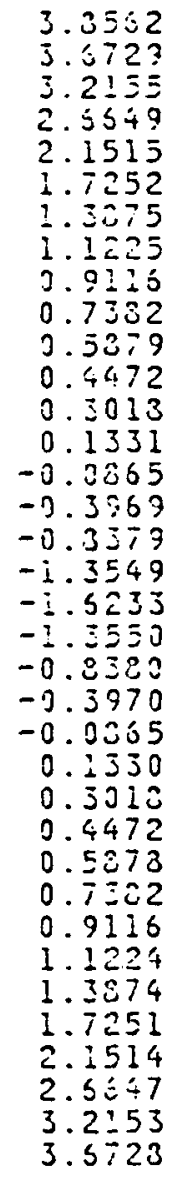 & $\begin{array}{r}0.0002 \\
-1.1973 \\
-2.1203 \\
-2.6055 \\
-2.3777 \\
-3.1020 \\
-3.1493 \\
-3.1741 \\
-3.2050 \\
-3.2701 \\
-3.3730 \\
-3.5262 \\
-3.7367 \\
-4.0023 \\
-4.2957 \\
-4.3005 \\
-4.2744 \\
-2.9013 \\
-0.0005 \\
2.9003 \\
4.2741 \\
4.5007 \\
4.2953 \\
4.0630 \\
3.7363 \\
3.5253 \\
3.3731 \\
3.2702 \\
3.2051 \\
3.1741 \\
3.1473 \\
3.1321 \\
2.9773 \\
2.3537 \\
2.1211 \\
1.1979\end{array}$ \\
\hline
\end{tabular}


LAMINATE FAILURE L OA D A NALLY S I S

LAYUP $\rightarrow-\rightarrow$ O $9090 \quad 0$

LAMI:AATE FAILURE LOADS BASED UPOI FIRST PLY FAILUPE CRITERIA (NO TEYPEPATURE OR MOISTURE STRESSES)

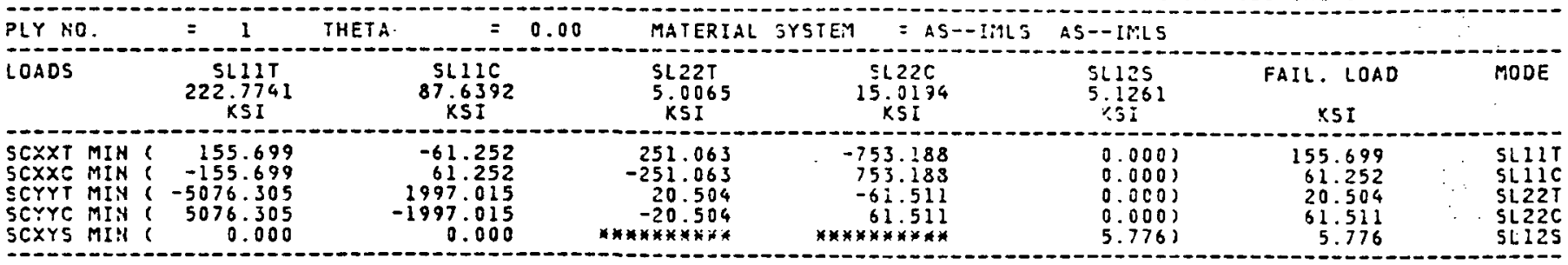

LAMINATE FAILURE LOADS BASED UPON FIRST PLY FAILURE CRITERIA (NO TEMPERATURE OF MOISTURE STRESSES)

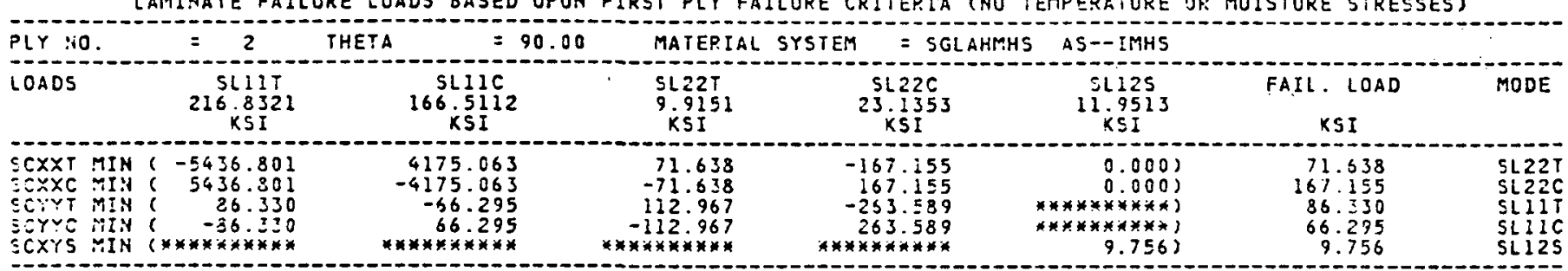

LAMINATE FAILURE LOAOS BASED UPON FIRST PLY FAILURE CRITERIA (NO TEMPERATURE OR MOISTURE STRESSES)

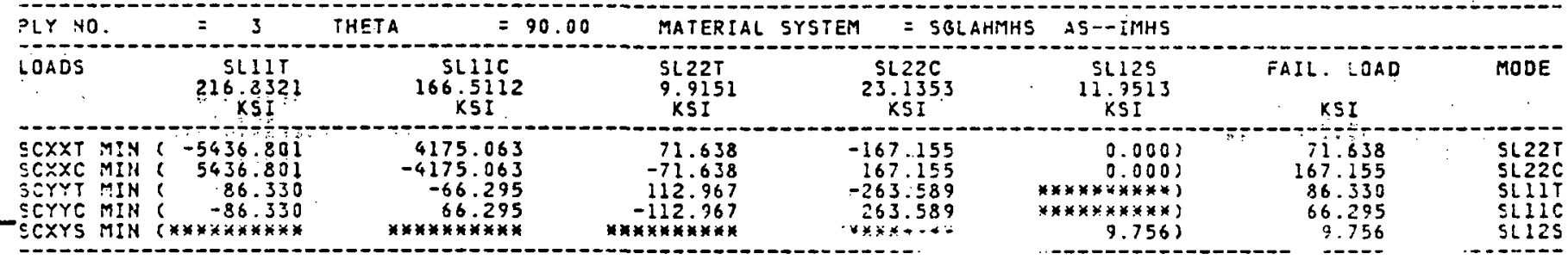

LAMIMATE FAILURE LOADS BASED UPON FIRST PLY F्ञ FIUURE CRITERIA (NO TEMPETATURE OR MOISTURE STRESSES)

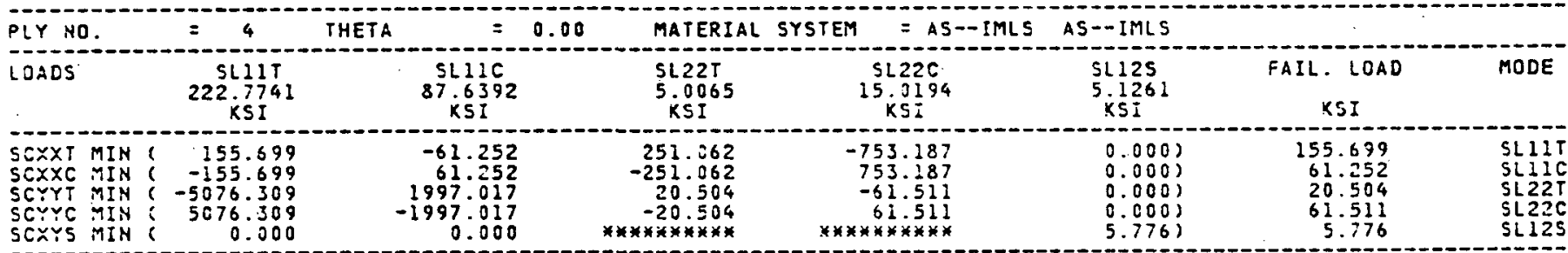

SU M M R Y

LAMINATE FAILURE LOAD ANALYSIS - (NO TEMPERATURE OR MOISTURE STRES5ES) (BASED UPON FIRST PLY FAILURE)

\begin{tabular}{|c|c|c|c|c|c|c|}
\hline AD TYPE & LOAD IN KSI & FAILURE MODE & PLY NO. & THETA & MATERIAL & SYSTEM \\
\hline $\begin{array}{l}\text { SCXXT } \\
\text { SCXXC } \\
\text { SCYYT } \\
\text { SCYYC } \\
\text { SCXYS }\end{array}$ & $\begin{array}{l}71.638 \\
61.252 \\
20.504 \\
61.511 \\
5.776\end{array}$ & $\begin{array}{l}\text { SL22T } \\
\text { SLIIC } \\
\text { SL22T } \\
\text { SL22C } \\
\text { SLI2S }\end{array}$ & $\begin{array}{l}3 \\
4 \\
1 \\
1 \\
4\end{array}$ & $\begin{array}{r}90.0 \\
0.0 \\
0.0 \\
0.0 \\
0.0\end{array}$ & $\begin{array}{l}\text { SGLAHMHS } \\
\text { AS--IMLS } \\
\text { AS--IMLS } \\
\text { AS--IMLS } \\
\text { AS--IMLS }\end{array}$ & $\begin{array}{l}\text { AS--IMHS } \\
\text { AS--IMLS } \\
\text { AS-IMLS } \\
\text { AS--IMLS } \\
\text { AS--IIILS }\end{array}$ \\
\hline
\end{tabular}

LAMINATE FAILURE LOAD ANALYSIS - (ND TEMPERATURE OR MOISTURE STRESSES) (BASED UPON FIBER FAILURE)

\begin{tabular}{|c|c|c|c|c|c|c|}
\hline LOAD TYPE & LOAD IN KSI & FAILURE MODE & PLY NO. & THETA & MATERIAL & SYSTEM \\
\hline $\begin{array}{l}\text { SCXXT } \\
\text { SCXXC } \\
\text { SCYYT } \\
\text { SCYYC } \\
\text { SCXYS }\end{array}$ & $\begin{array}{r}155.699 \\
61.252 \\
86.330 \\
66.295 \\
\times \times \times \times \times \times 3\end{array}$ & $\begin{array}{l}S L I 1 T \\
\text { SLIIC } \\
\text { SLIIT } \\
\text { SLIIC } \\
K / A\end{array}$ & $\begin{array}{l}4 \\
4 \\
2 \\
2\end{array}$ & $\begin{array}{r}0.0 \\
0.0 \\
90.0 \\
90.0\end{array}$ & $\begin{array}{l}\text { AS--IMLS } \\
\text { AS--IMLS } \\
\text { SGLAHMHS } \\
\text { SGLAHMHS }\end{array}$ & $\begin{array}{l}\text { AS--IMLS } \\
\text { AS--IMLS } \\
\text { AS--IMHS } \\
\text { AS--IMHS }\end{array}$ \\
\hline
\end{tabular}

NOTE: IF THERE IS NO ANGLE PLY "SCXYS" BASED UPON FIBRE FAILURE IS NOT PREDICTED. 


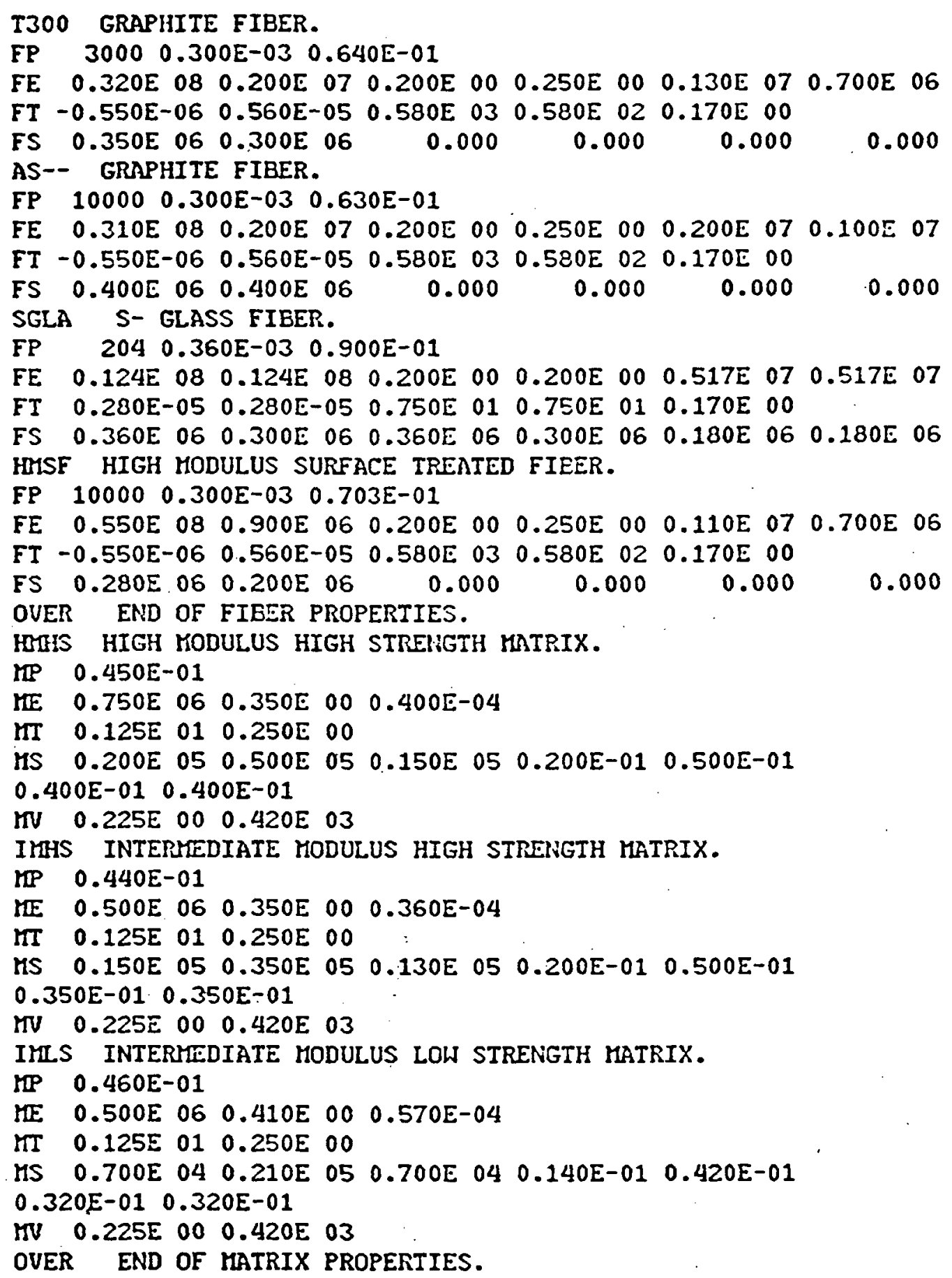




\section{REFERENCES}

1. Chamis, C. C., "Design Oriented Analysis and Synthesis of MultilayeredFllamentary Structural Panels," Ph.D. Thesis, Case Western Reserve University, Cleveland, Ohio, 1967.

2. Chamis, C. C., "Computer Code for the Analys is of Multilayered Fiber Composites - User's Manual," NASA TN D-7013, 1971.

3. Chamis, C. C. and Sinclair, J. H., "Prediction of Properties of Intraply Hybrid Composites," NASA TM-79087, 1979.

4. Chamis, C. C. and Sinclair, J. H., "Micromechanics of Intraply Hybrid Composite: Elastic and Thermal Properties," NASA TM-79253, 1979.

5. Chamis, C. C., Lark, R. F. and Sinclair, J. H., "Mechanical Property Characterization of Intraply Hybrid Composites," NASA TM-79306, 1979.

6. Chamis, C. C., Lark, R. F. and Sinclair, J. H., "An Integrated Theory for Predicting the Hydrothermomechanical Response of Advanced Composite Structural Components," NASA TM-73812, 1977.

7. Chamis, C. C. and Sinclair, J. H., "INHYD: Computer Code for Intraply Hybrid Composite Design," NASA TP-2239, 1983.

8. Murthy, P. L. N. and Chamis, C. C., "ICAN: Integrated Composite Analyzer Users and Programmers Manua 1. NASA TP in preparation, 1984.

9. Pagano, N. J. and Pipes, R. B., "Some Observations on the Interiaminar Strength of Composite Laminates," International Journal of Mechanical Sciences, Vol. 15, No. 8, 1973, pp. 679-688.

10. Lekhnitski1, S. G. and Brandstatter, J. J., eds., Theory of Elasticity of an Anisotropic Elastic Body, Holden-Day, San Francisco, 1963.

11. Chamis, C. C. and Smith, G. T., "CODSTRAN: Composite Durability Structural Analysis," NASA TM-79070, 1978.

12. Chamis, C. C. and Minich, M. D., "Structural Response of a Fiber Composite Compressor Fan Blade Airfo11," NASA TM X-71623, 1975.

13. Chamis, C. C. and Sinclair, J. H., "Analys is of High Velocity. Impact on Hybrid Composite Fan Blades," NASA TM-79133, 1979. 
TABLE I. - ICAN: 'SAMPLE INPUT DATA

Four ply symmetric laminate. ICAN sample input data.

\begin{tabular}{|c|c|c|c|c|c|c|c|c|}
\hline $\begin{array}{l}\text { STDA } \\
T \\
F \\
F \\
F \\
T\end{array}$ & 4 & 1 & 2 & & & & & \\
\hline $\begin{array}{l}\text { PLY } \\
\text { PLY } \\
\text { PLY } \\
\text { PLY }\end{array}$ & $\begin{array}{l}1 \\
2 \\
3 \\
4\end{array}$ & $\begin{array}{l}1 \\
2 \\
2 \\
1\end{array}$ & $\begin{array}{l}70.00 \\
70.00 \\
70.00 \\
70.00\end{array}$ & $\begin{array}{l}70.0 \\
70.0 \\
70.0 \\
70.0\end{array}$ & $\begin{array}{r}0.0 \\
.0 \\
.0 \\
.0\end{array}$ & $\begin{array}{r}0.0 \\
90.0 \\
90.0 \\
90.0\end{array}$ & $\begin{array}{r}0.010 \\
.005 \\
.005 \\
.010\end{array}$ & \\
\hline \multicolumn{3}{|c|}{$\begin{array}{l}\text { MATCRDAS- -IMLS } \\
\text { MATCROSGLAHMHS } \\
\text { PLOAD } 1000 . \\
\text { PLOAD } 0.0 \\
\text { PLOAD } 0.0\end{array}$} & $\begin{array}{l}0.55 \\
0.55 \\
0.0 \\
0.0 \\
0.0\end{array}$ & $\begin{array}{l}0.02 \\
.01 \\
0.0 \\
0.0\end{array}$ & $\begin{array}{l}\text { AS--IMLS } \\
\text { AS--IMHS } \\
0.0\end{array}$ & $\begin{array}{r}0.0 \\
.4 \\
\end{array}$ & $\begin{array}{r}0.57 \\
.57\end{array}$ & $\begin{array}{r}0.03 \\
.01\end{array}$ \\
\hline
\end{tabular}




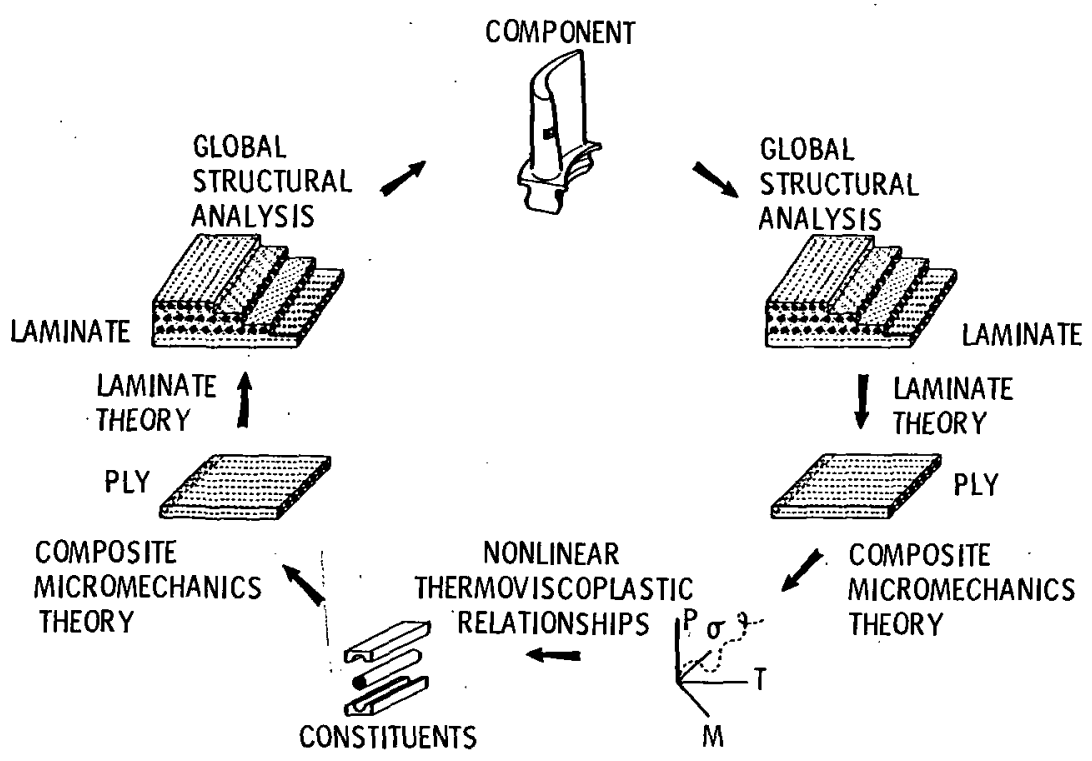

MATERIAL PROPERTIES

$P(\sigma, T, M)$

Figure 1. - Upward integrated and top-down traced structured theory.

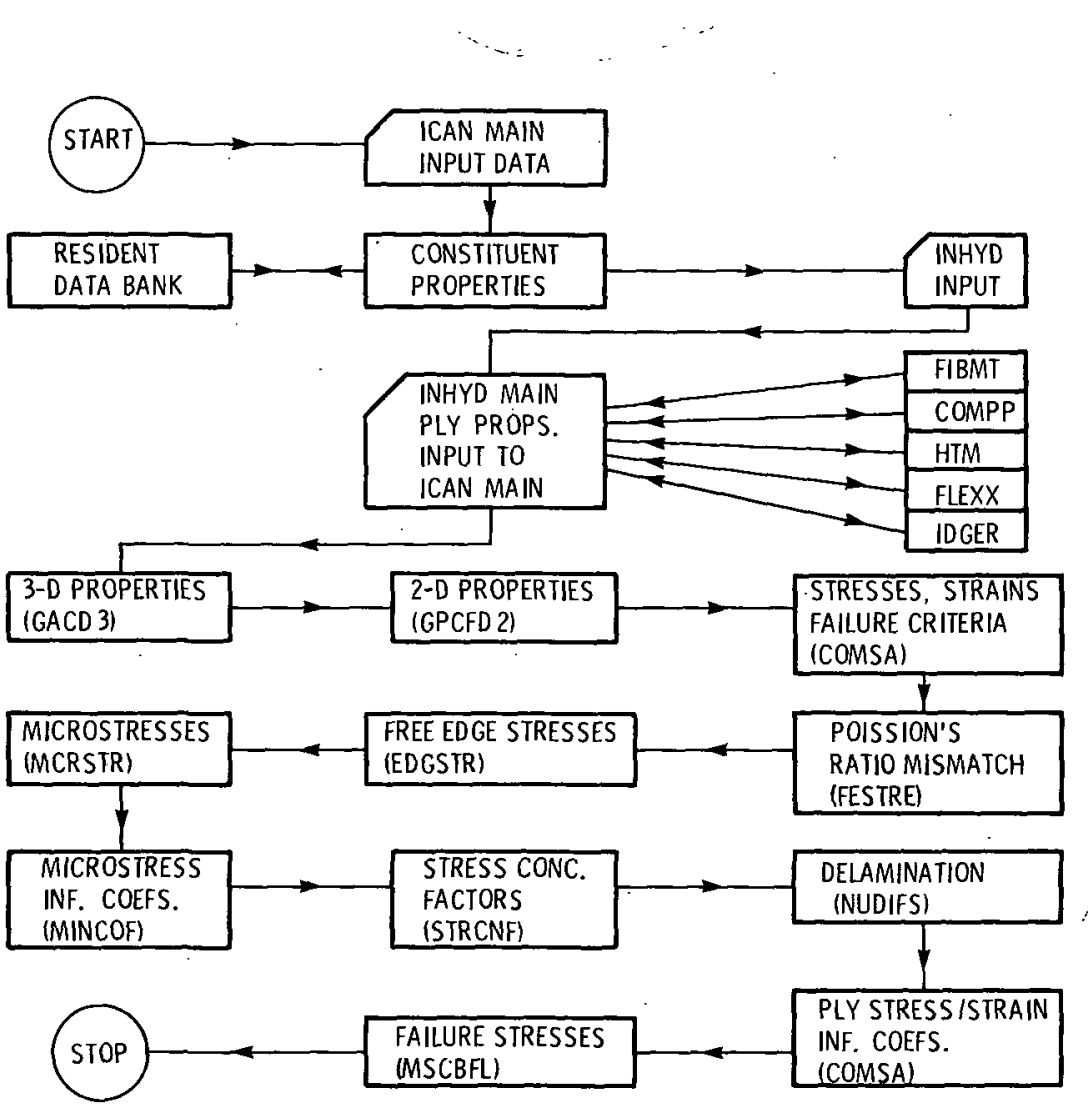

Figure 2. - ICAN: flow chart. 


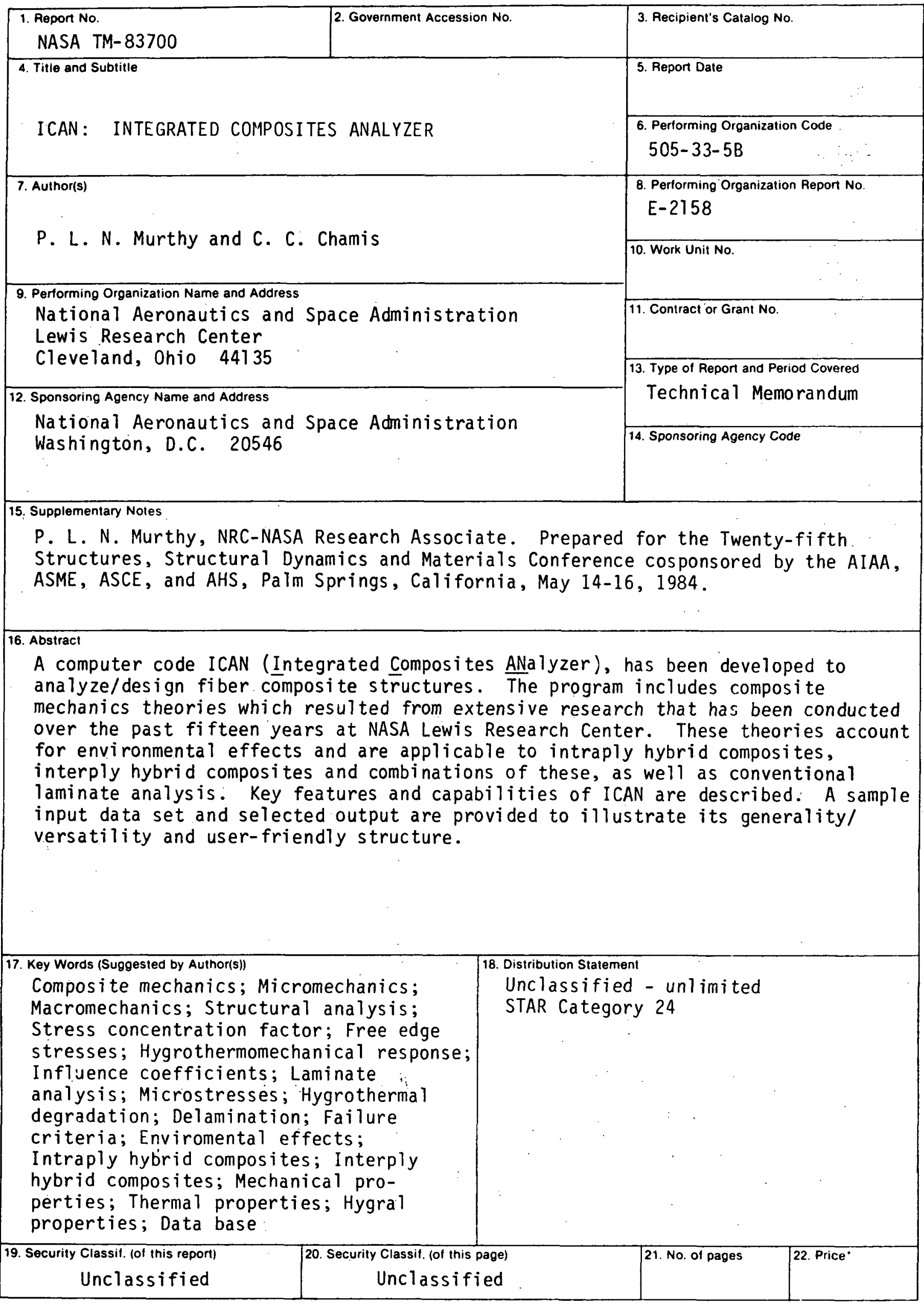


National Aeronautics and Space Administration

Washington, D.C.

20546

Olficial Business

Penally for Privale Use, $\$ 300$
SPECIAL. FOURTH CLASS MAIL BoOK

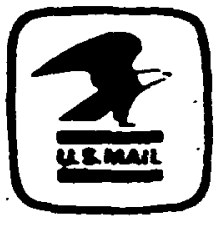

Pontege and Fees Paid Nrtional Aeroneutics and Spece Administrotion NASA-451 